\title{
Quranic verse finder: a tool for speech preparation using quranic verses
}

\author{
Maslina Abdul Aziz ${ }^{1}$, Irfan Fikri Azni², Wan Faezah Abbas ${ }^{3}$, Mohd Izuan Hafez ${ }^{4}$, \\ Nur Nafhatun Md Shariff ${ }^{5}$ \\ 1,2,3 Faculty of Computer and Mathematical Sciences, UiTM Shah Alam, Malaysia \\ ${ }^{4}$ Department of Computer Science, Faculty of Computer Science and Information Technology, Putra University Malaysia \\ ${ }^{5}$ of Contemporary Islamic Studies, UiTM Shah Alam, Malaysia
}

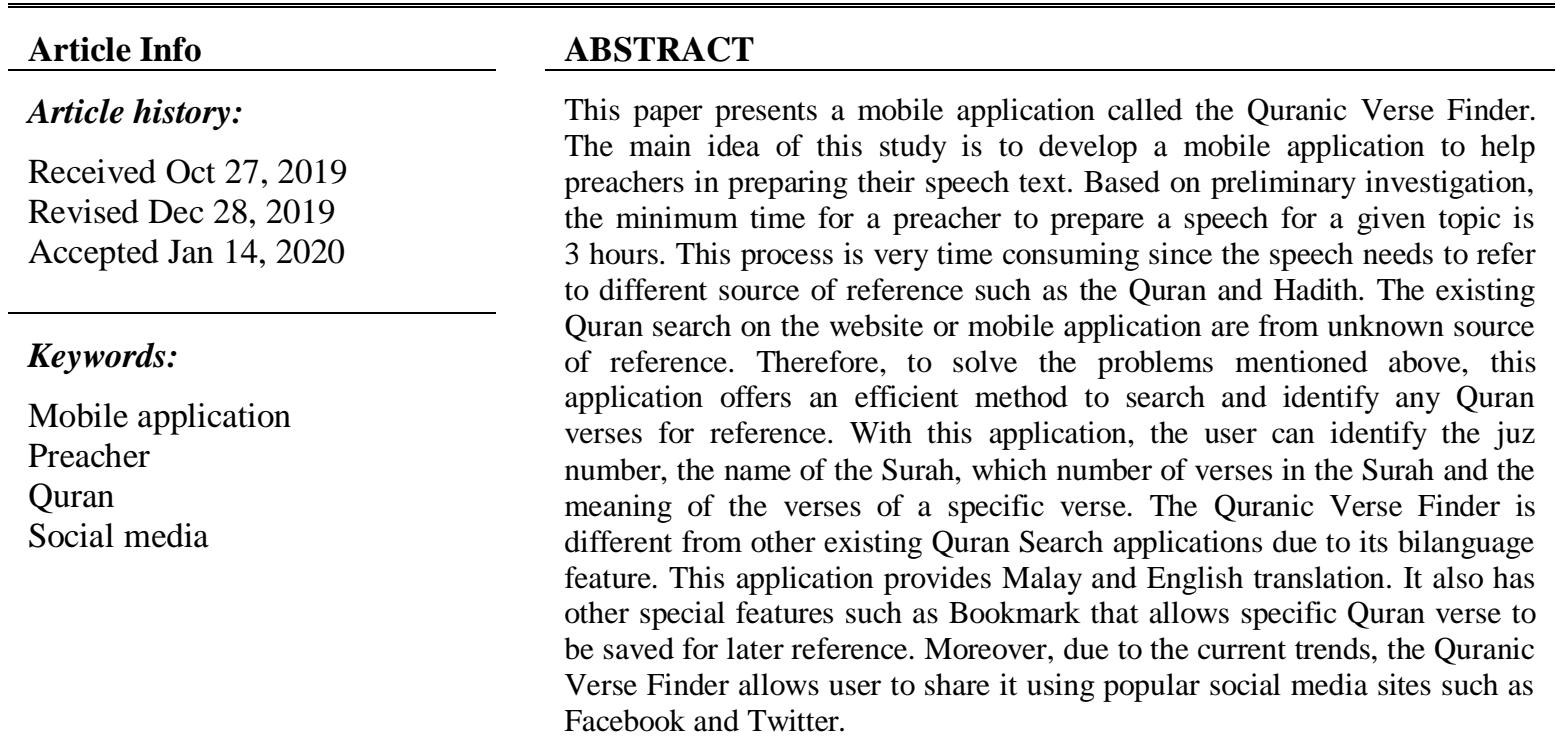

Copyright $@ 2020$ Institute of Advanced Engineering and Science. All rights reserved.

\section{Corresponding Author:}

Masllina Abdul Aziz,

Faculty of Computer and Mathematical Sciences,

UiTM Shah Alam, Selangor, Malaysia.

Email: maslina@tmsk.uitm.edu.my

\section{INTRODUCTION}

Mostly, Islamic preacher, especially Ustaz and Ustazah take a lot of time to prepare their speech. In order to deliver a speech or talk, an Islamic preacher will need to refer to various sources of information especially Quran, Hadith, authoritative books and other relevant sources. To write a good speech, they must have many authentic sources to convince the audience. They need to refer up to 10 relevant sources to prepare each speech. For a topic like "Haji" or Haj, the Islamic preacher need to look it up in the Quran and it will be difficult to find a word or verse related to the topic. This is a time-consuming process. Plus, it is hard for them to find particular verses, what number of verses, which surah name and what juz for that particular verse. There is a high possibility of mistake when doing the search of the Quran's verse manually and hadith. Currently, there are existing applications and websites that can search the word in the Quran correctly. However, current existing applications and websites have lots of limitations such as, the search only can be done in Arabic and English words. Moreover, the validity of source of reference with existing Quran search website and application available cannot be guaranteed. The development of The Quranic Verse Finder allows to use search engine and enables keyword searching from the al Quran. This tool enables Islamic 
preachers to get gather relevant information from the reliable sources with the option for different languages especially Malay.

Existing Quran search websites and applications are mostly in English. It is hard for preachers in generally in local universities Malaysia that teaches and speaks Malay language to Malay audience. Currently they refer to the Quran that has Malay translation as a source of reference, which is done manually. This research aims to provide a search engine tool on a mobile application platform for the Islamic Preacher in assisting them in preparing speech or presentation. Among the benefits are easier for Islamic preacher to manage the speech sources, it can also be used as teaching tools, easier to find specific verse of the Quran to use, save more time to find the sources for the content since it is bilingual and the source for the content is accurate. Other existing research on Quran verse is also available such as Quranic Verse Recitation Recognition Systems [1]. This research provides a comprehensive review of Quran Arabic verse recitation recognition in support of j-QAF learning. This paper presents a mobile application called the Quranic Verse Finder to help preachers in preparing their speech text in a faster and efficient manner.

\section{LITERATURE REVIEW}

In Islam there are only two original sources of knowledge and guidance; the Holy Quran and the Sunnah of the Prophet. However, some people have difficulties in reading and understanding the words in the Quran and Hadith. One of the problem identified is some people are unfamiliar with the Qur'an. The Quran can be described as sacred text and it is in the Arabic language. Even though there is Quran translator available, however it needs deeper understanding. Without knowledge about the Quran and Hadith might create problems and confusion. Ibn Katheer reported in his 'Tafseer' that Mujahid said: This is the number of the letters of the Qur'an as we counted them: 320,015 letters. As for its verses, their number is: more than 6000 verses. Some scholars say it is 6236 verses and There are 114 surah (chapters) in the Quran with there are 30 Ajza' (volumes/parts) to the Quran. That means, it takes time until we want to find one or more than one verse to refer what is the verse number, what is the surah name and which juzuk it from 6236 verses. There are 114 surah (chapters) in the Quran and 30 Ajza' (volumes/parts) to the Quran [2]. The Quran contains 43 different languages including Arabic, Amharic and Amazigh [3]. Some words can be repeated a lot of times in the Quran verses. This is a time-consuming process. Therefore, with the existence of an application that allows to use search engine and enables keyword searching from the Quran. This tool it will ease and assist the Islamic preachers to get gather relevant information from the reliable sources efficiently and saved it for speech preparation. Moreover, it can also be a learning tool that be used as an alternative teaching method in classroom [4-6].

\subsection{Keyword Search}

A keyword is a word or expression ordinarily an expression of a few words which has been distinguished as one which potential users utilize when they are looking through the web. Keyword is widely use in retrieving result in queries [7]. Users send queries by typing certain word or phrase. Based on the keyword, user will be a list of results and findings based on query of word / phrase. The technique help user in discovering the words that individuals' sort in web indexes and the relationship between data items. Some examples of cases are Google look, Yahoo seek, Bing look and some more. Keyword search is known as part of search that looks for matching documents that contain one or more words specified by the user [8]. Other than that Columbia University Library (2017) defined a keyword search for words anyplace in the record. Keyword search looks are a decent substitute for a subject pursuit when you don't have the foggiest idea about the approved subject heading structure [9]. Keyword search may likewise be utilized as a substitute for a title or creator seeks when inadequate titles or creator data haven.

\subsection{Information Retrieval}

Information retrieval is the method of recovering relevant information from various unstructured information to produce meaningful result. Research proved the conventional IR techniques can be used to search and retrieve information on Malay documents [10]. A catchphrase-based inquiry technique utilized to recover the significant content record of the ordered content documents that are important for the client. Other than that, Information retrieval models have been utilized not just in the retrieval of content archives from different computerization systems, yet have likewise been utilized as a part of different fields of common dialect preparing [11-13]. Other than that, Hiemstraan (2009) said information retrieval system is a product program that stores and oversees data on archives, frequently printed reports yet potentially sight and sound [14]. The system helps clients in finding the data they require. It doesn't unequivocally return data or answer questions. Rather, it advises on the presence and area of records that may contain the coveted data. 
According to Savolainen (2016), information seeking to become widely known as received meaning of normal for data inquiry and information retrieval [15]. Be that as it may, because of the prominence of web seeking, information retrieval is progressively in view of direct end-client looking by the on-screen characters themselves. Consequently, data hunt and information retrieval can be viewed as covering classifications with regard to the web looking specifically. Like the terms information seeking and information searching, there are different meanings of the ideas of information seeking strategy (ISS) and data searching system, and related terms, for example, data seek strategies and information retrieval strategies. ISS and data seek methodology are broadly utilized as a part of the above field yet their connections are undefined [15].

\subsection{Information Retrieval Model}

The concept of information retrieval rests on the usage of two basic models of information retrieval which are Boolean model and Vector model. Investigating the two essential models of information retrieval, we discover that the information retrieval models are fundamentally the distinctive routes by which one would be empowered to discover the correct report that would satisfy one's necessities. These ways are either customary ways that search up for correct matches or the whimsical ways that have the approach of incomplete coordinating $[13,16]$.

\subsubsection{Boolean Model}

According to Khan (2014), Boolean model utilize the customary methodologies in which the correct match of the inquiry is found and the recovered question fulfilling the client needs [17]. Aside from understanding the models of the different web looks, it is additionally critical for us to discover the spots where each model can be more helpful when contrasted with alternate models. Basically, the Boolean model is a customary model that works with the basic guideline of finding the archive coordinating the correct terms of the query. The Boolean model does not perform fractional matches. The concept of $0 \mathrm{~s}$ as followed in the Boolean variable-based mat-either yes or no, or, as such, either an archive of correct match is found or it isn't found [13].

\subsubsection{Vector Space Model}

Vector space demonstrates, dissimilar to the Boolean model has the approach of incomplete coordinating. Vector space demonstrates utilized the eccentric strategies for recovering the data in which the recovery of data is done through the fractional matches. Vector space show gives much better outcomes as contrasted and the Boolean model of data recovery. Vector space show gives consequences of 'about correct matches', in which now and then such archives are likewise discovered which may not be totally valuable, but rather might be used to some degree. A vector similitude measure is utilized for positioning the recovered reports. This measure is ascertained between the question and documents. The length and heading of their vectors are utilized to ascertain it [18].

\subsection{Existing Search Engine Tools}

A web search engine is an apparatus that enables individuals to discover data on the internet [19]. The internet is huge to the point that is completely difficult to discover all website pages that reference bother control administrations. Search engine is a web programming system or electronic content accessible over the Internet that scans records and documents for watchwords and returns the rundown of results containing those watchwords. Today, there are quantities of various web crawlers accessible on the Internet, each with their own procedures and claims to fame [20]. Search engines arrive in various setups that mirror the applications they are intended for Web search tools, for example, Google and Yahoo!, must have the capacity to catch, or slither, numerous terabytes of information, and after that give sub second reaction times to a great many inquiries presented each day from around the globe [21]. Table 1 shows the comparison between the features of the tools.

Table 1. The Comparison Between Quran Phonetic Search and Ayah Filter: Search in Quran

\begin{tabular}{|c|c|c|}
\hline $\begin{array}{l}\text { Existing } \\
\text { Tools }\end{array}$ & Quran Phonetic Search [22] & Ayah Filter: Search in Quran [23] \\
\hline $\begin{array}{l}\text { Search } \\
\text { Language }\end{array}$ & $\begin{array}{l}\text { This website can only search in English and Roman } \\
\text { alphabet spell in Arabic. }\end{array}$ & This application only can search in Arabic. \\
\hline The Result & $\begin{array}{l}\text { The result will be displayed only in English and Arabic. } \\
\text { It shows all the synonym words of the search word. }\end{array}$ & $\begin{array}{l}\text { The result will be displayed only in English and Arabic. } \\
\text { It will show only the exact search word }\end{array}$ \\
\hline Sorting & The result sorted based on number of surah in the Quran. & The result sorted based on number of surah in the Quran. \\
\hline History & $\begin{array}{l}\text { There is no repository to save and bookmarks the history } \\
\text { of previous search. }\end{array}$ & $\begin{array}{l}\text { There is no repository to save and bookmarks the history } \\
\text { of previous search. }\end{array}$ \\
\hline
\end{tabular}

Indonesian J Elec Eng \& Comp Sci, Vol. 18, No. 3, June 2020 : 1616 - 1623 
There are few existing website and application available that have similar function on text search which has been studied, i.e. Quran Phonetic Search (website) and Ayah Filter: Search in Quran (application). This comparison of existing website and application between Quran Phonetic Search and Ayah Filter: Search in Quran. Both website and application have its own features and design.

\section{METHODOLOGY}

The Quranic Verse Finder is new application that uses the Quran as components in this application. This application is suitable for people that use it as a reference and better understanding. For example, as students, they can use this application when they attend Quran class. Besides that, the Quranic Verse Finder can be used anywhere the user wants to use it. The users can download this application in Google Play Store and also in Apps Store. The Quranic Verse Finder is developed based on Google Search Engine function. For instances, the user just needs to type what they want to search such as "Haji" then all verses from the Quran that relates to the "Haji" topic will be listed according to the Surah order. The Quranic Verse Finder make use of the keyword search method. The word entered by the user will be traced and search throughout the Quran. The word that matches the exact word in the Quran verse will be listed. The steps of the search are depicted in Figure 1.

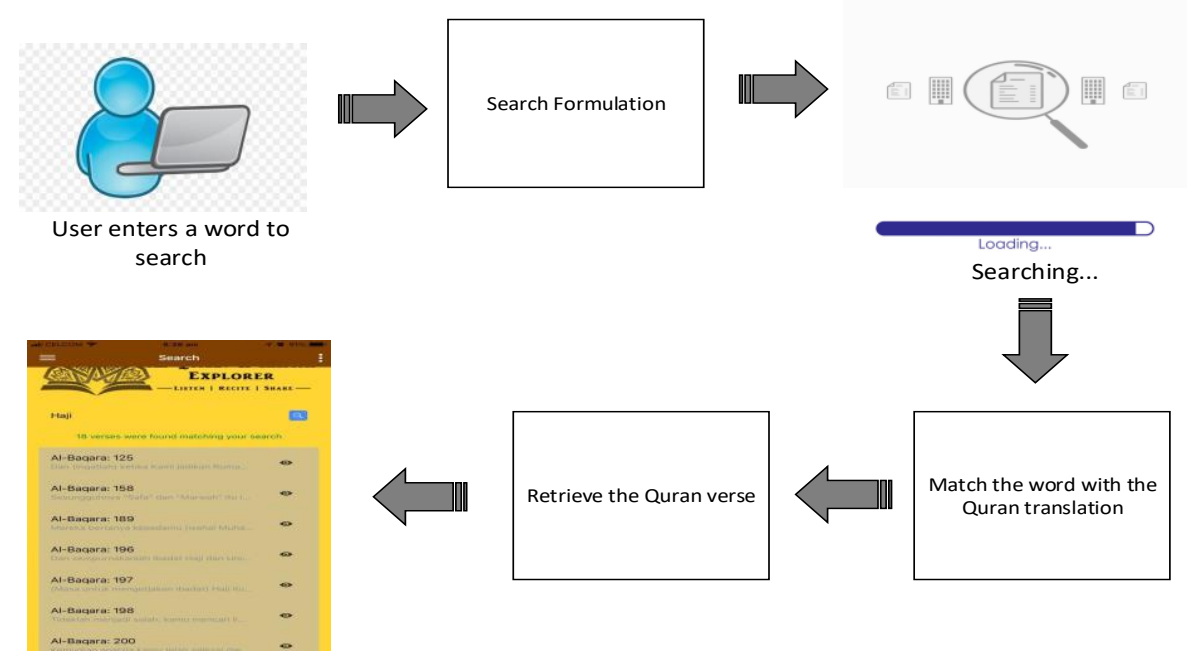

Figure 1. The search and match steps

\subsection{Mobile Application Development Life Cycle (MADLC) Model}

Mobile application development life cycle (MADLC) has known as framework created by Intel IT to define particular activities, tools and resources, to support the planning, development and deployment of mobile applications [24]. In MADLC model, there are seven phases which are identification, design, development, prototyping, testing, deployment and maintenance. In the primary stage, identification phase, the ideas are gathered and classified. The main objective of this phase is to get new ideas or changes to the current application. The client or the developers can come out any ideas to be further detailed and analysed by brainstorming to get new ideas for new application.

In the design phase, the idea developed into the visual form such as storyboard, paper prototype and user and system interface. The achievability of building up the application on all versatile stages is resolved. On the other hand, the particular target portable stage is recognized. A choice must be made on whether the created application is to be discharged as a free form or trial adaptation with constrained highlights or discharged just as a top-notch variant. The third phase is development phase. In this phase, the process of coding will be started in the application. The development process has two stages which are Coding for Functional Requirement and Coding for User Interface requirements. First stage, functional requirement needs to be fulfilled follow the requirement and prototype. Second stage, user interface is designed according to the storyboard and make sure it can be supported on as many mobile operating systems as possible.

In prototyping phase, prototyped are analysed of its functional requirement by testing and sent to the client for feedback. The changes are implemented on development phase again depends on feedback received. The first and second prototype must be integrated once second prototype is ready to tested and sent 
to the client. When the final prototype is ready, it is sent to the client for a final feedback and result will be documented. In any development lifecycle model, testing phase is one of the most important phases. Prototype is performed and tested on the emulator and real device. On the real device, the prototype needs to be tested on multiple operating system versions and models of device with different screen size. For this application, it uses Ionic Cross-Platform Mobile Application Development to make sure it is flexible to different types of platforms. The final phase of the development process is deployment. After previous phase is done and completed, the application is uploaded to appropriate application market for user to download and use.

\section{RESULTS AND ANALYSIS}

\subsection{Quranic Verse Finder Mobile Application}

The Quranic Verse Finder design based on three characteristic which includes performance, reliability and special features. Firstly, the main performance of Quranic Verse Finder is to help the user to find anything or to gain more information that related with the Quran verses with meaning and related Hadith. This Quranic Verse Finder will give all possible result of the Quran verses with the number of verses, name of the Surah, number Juzuk and the verse's meaning plus Hadith that related with want user want to see by only insert word as an input to Quranic Verse Finder. Besides that, we Quranic Verse Finder is easier to use and accessible for the performance. Quranic Verse Finder is an application that easy to use and accessible because all the features or icon that we use as the interface of Quranic Verse Finder is simple to understand such as common symbols that can understood easily. Next, we make Quranic Verse Finder accessible anytime and anywhere as long that as the user have internet access using any types of device rather than traditional manual search method or ask expert such as Ustaz or Ustazah.

Figure 2 shows that main page of the Quranic Verse Finder application. The front page of this application designed simple and using common icon for searching. The search bar allows user to type in the required word. After the user presses the search icon, the results will be displayed. The results of the search are shown in Figure 3. The application will list all of the verses in the Quran that relates to the searched keyword from different Surah. If the user finds the suitable verse that he or she likes, the Quran verse can be bookmarked for later use. The verse will be saved in text format. Due to the current trends, some users prefer to share knowledge, thoughts and views on the social media platform. Therefore, the Quranic Verse Finder has the feature of sharing the particular Quran verse via three popular social media platform; Twitter, Facebook and Google as shown in Figure 4.

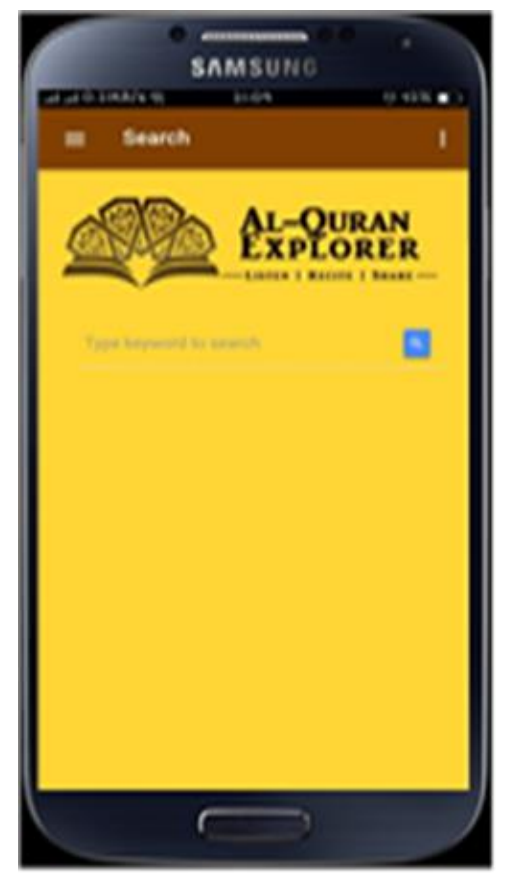

Figure 2. The front page of the mobile application

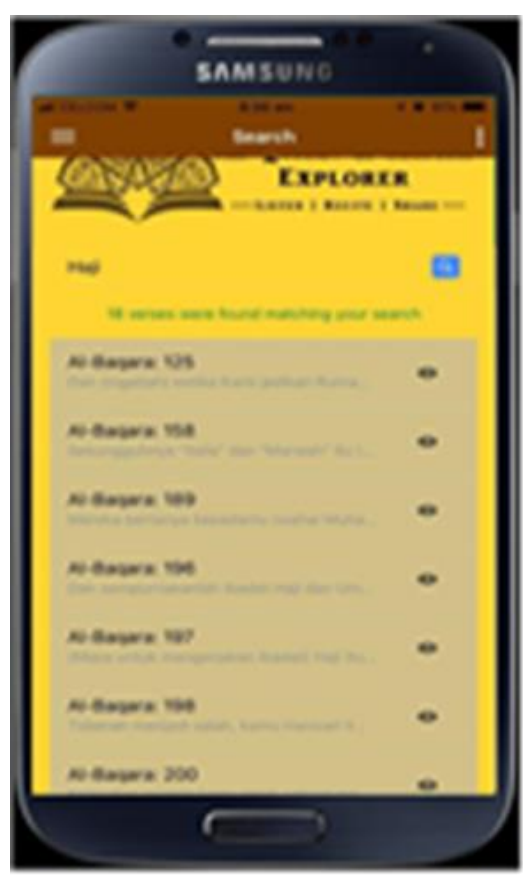

Figure 3. The result of the search 


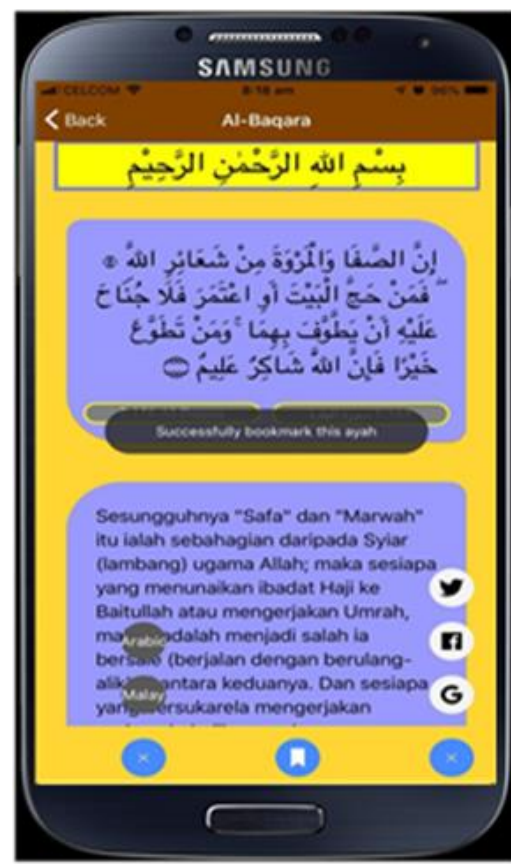

Figure 4. The features of Quranic verse finder

\subsection{Validation Test}

To test the ability of this product to break through the market, a set of questionnaires are being distributed among students and other people. This test marketing is important to see whether this product is feasible and will be able to earn profit if it is produced. Our application which is Quran can really benefit the users due to its reliability, accessibility, time saving and with other additional features. Our respondents are students from Universiti Teknologi MARA (UiTM). The total respondents are 42 people. From the result we can summary that, most of the response we get from the respondents are positive. This is to be expected since our application are better than the other product. We also found out that it is important to have an application that can help them that related to the Quran.

Next, the respondents also gave positive response about Quranic Verse Finder application that can help them get the specific verse in the Quran in a fast manner. This application is very helpful and useful for preacher/lecturer to get the verse in the Quran as reference when writing a speech. Besides that, most of the respondents also agreed that this Quranic Verse Finder can save their time since the translation provided in Malay language [25]. As mentioned before most websites or applications available only provide the Quran translation in Malay. Furthermore, we also ask about all the features in our application. As the result, most pf the respondents agree that the Quranic Verse Finder needs to add more features such as Kiblah Direction, Prayer Time and Audio for the user to hear the Quran verses. Last but not least, most of respondent gave positive feedbacks on Quranic Verse Finder as this application can be used not only for work such for speech or preaching but also it can also be used as study or research tool.

\section{CONCLUSION}

This paper presented a mobile application called the Quranic Verse Finder. The main idea of this study is to develop a mobile application to help preachers in preparing their speech text. The Quranic Verse Finder is feasible for the user since it saves more time with faster result output for speech preparation. Quranic Verse Finder uses the current mobile technology that caters for social media users. The Quranic Verse Finder can be one of the ways to preach using social media since it has potential to attract and encourage teenagers by sharing the knowledge of the Quran. Moreover, this application provides Malay translation with accurate result of the Quran. The result of retrieved were verified by experts to avoid any fake or mistakes. 


\section{ACKNOWLEDGEMENTS}

The authors gratefully acknowledge Faculty Computer and Mathematical Sciences of Universiti Teknologi Mara, Malaysia for the support of this research. Special thanks to all of students especially Nuha Nashriq Bin Hasan Sazalli, Abdul Shukur Bin Mat Yusof, Mohammad Hafiz Bin Zuraimi from group Khasif from the subject ENT600 March 2018 for significant contribution to this research. Moreover, we would like to voice out our appreciation to Academy of Contemporary Islamic Studies (ACIS) especially Ustaz Mohd Hafiz Mohd Hasan which is the Head of Guidance and Education Center and Ustazah Wan Razifah Wan Ahmad that is the Second Deputy Director of ACIS for all the guidance and knowledge for this research.

\section{REFERENCES}

[1] Ibrahim, Noor Jamaliah, et al. "Quranic Verse recitation recognition module for support in J-QAF learning: A Review." Int. J. Comput. Sci. Netw. Secur. 8.8, pp. 207-216, 2008.

[2] Sembok, Tengku Mohd T., Zainab Abu Bakar, and Fatimah Ahmad. "Experiments in Malay information retrieval." Proceedings of the 2011 International Conference on Electrical Engineering and Informatics. IEEE, 2011.

[3] Sherif, Mohamed Ahmed, and Axel-Cyrille Ngonga Ngomo. "Semantic Quran." Semantic Web, 6.4, pp. 339-345, 2015.

[4] Tahir, Zurainee Mohd, Haryani Haron, and Jasber Kaur. "A Review of Ubiquitous Language Learning Environment." Indonesian Journal of Electrical Engineering and Computer Science (IJEECS), 12.1, 275-281, 2018.

[5] Noor, Norlenda Mohd, et al. "Development of Learning Tools using Maples for Engineering Mathematics Subject." Indonesian Journal of Electrical Engineering and Computer Science (IJEECS), 9.1, 131-138, 2018.

[6] Tahir, Zurainee Mohd, Haryani Haron, and Jasber Kaur Gian Singh. "Evolution of learning environment: A review of ubiquitous learning paradigm characteristics." Indonesian Journal of Electrical Engineering and Computer Science (IJEECS), 11.1, pp. 175-181, 2018.

[7] Mohammed, Ammar, Mohd Shahrizal Sunar, and Md Sah Hj Salam. "Quranic verses verification using speech recognition techniques." Jurnal Teknologi, 73.2, 2015.

[8] Keyword search. (n.d.). In Webopidia. Retrieved 7 July, 2019, from https://www.webopedia.com/TERM/K/keyword_search.html.

[9] Columbia University Library. (2017). Retrieved November 21, 2017, from http://www.columbia.edu/cu/lweb/help/clio/keyword.print.html.

[10] Zulkefli, Nurul Syeilla Syazhween Binti, et al. "Effectiveness of Latent Dirichlet Allocation Model for Semantic Information Retrieval on Malay Document." 2018 Fourth International Conference on Information Retrieval and Knowledge Management (CAMP). IEEE, 2018.

[11] Zainudin, Mohamad Khairul Annuar B., and Riaza Mohd Rias. "M-Hadith: Retrieving Malay Haditli text in a mobile application." 2012 International Symposium on Computer Applications and Industrial Electronics (ISCAIE). IEEE, 2012.

[12] Raman, Shivangi, Vijay Kumar Chaurasiya, and Swaminathan Venkatesan. "Performance comparison of various information retrieval models used in search engines." 2012 International Conference on Communication, Information \& Computing Technology (ICCICT). IEEE, 2012.

[13] Hiemstra, Djoerd. "Information retrieval models." Information Retrieval: searching in the 21st Century, pp. 1-17, 2009.

[14] Din, Noorriati, Saadiah Yahya, and Shireen Haron. "Information retrieval and academic performance among Facebook users." Procedia-Social and Behavioral Sciences, 68, pp. 258-268, 2012.

[15] Savolainen, Reijo. "Information seeking and searching strategies as plans and patterns of action: A conceptual analysis." Journal of Documentation, 72.6, pp. 1154-1180, 2012.

[16] Jiang, Hua. "Study on the performance measure of information retrieval models." 2009 International Symposium on Intelligent Ubiquitous Computing and Education, pp. 436-439, 2009.

[17] Khan, Javed Ahmad. "Comparative study of information retrieval models used in search engine." In 2014 International Conference on Advances in Engineering \& Technology Research (ICAETR-2014), pp. 1-5, 2014.

[18] Khari, Manju, Amita Jain, Sonakshi Vij, and Manoj Kumar. "Analysis of various information retrieval models." In 2016 3rd International Conference on Computing for Sustainable Global Development (INDIACom), pp. 2176-2181. IEEE, 2016.

[19] Kumar, A. (2017). "Introduction to Search Engines and Search Engine Optimization". Downloaded November 9, 2017, from softnik.com/download/seobasics.pdf.

[20] Jain, Ayush. "The Role and Importance of Search Engine and Search Engine Optimization." International Journal of Emerging Trends \& Technology in Computer Science, 2.3, pp. 99-102, 2013.

[21] Croft, W. Bruce, Donald Metzler, and Trevor Strohman. Search engines: Information retrieval in practice. Vol. 520. Reading: Addison-Wesley, 2010.

[22] Retrieved January 9, 2019 from https://www.islamicity.org

[23] Retrieved January 9, 2019 from https://ayah-filter.soft112.com/ 
[24] Darus, Mohamad Yusof, Mohd Shafiq Akmal Hazani, and Norkhushaini Awang. "Mobile Self-Management System for University Students using Mobile Application Development Lifecycle (MADLC)." Journal of Telecommunication, Electronic and Computer Engineering (JTEC), 9.3-4, pp. 11-14, 2017.

[25] Hanum, Haslizatul Mohamed, et al. "Using topic analysis for querying halal information on Malay documents." Procedia-Social and Behavioral Sciences, 121, pp. 214-222, 2014.

\section{BIOGRAPHIES OF AUTHORS}

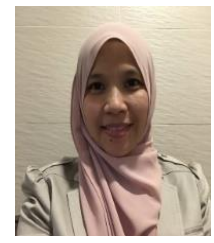

Dr. Maslina Abdul Aziz is a Senior Lecturer at Universiti Teknologi MARA, Malaysia. She holds a $\mathrm{M}(\mathrm{E})$ in Software from University of Queensland, Australia. She also obtained a PhD from Deakin University, Australia. She worked as an Executive at Multimedia Development Corporation (MDec) in Cyberjaya. Her research interests are Systems and Software/Systems Engineering and Industrial Informatics. She is a member of International Association of Engineers (IAENG) and a Professional Technologists from Malaysia Board of Technologists (MBOT). Her research area also includes E-commerce as she is certified as Alibaba Trainer.

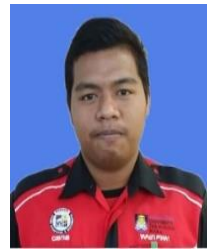

Irfan Fikri Azni graduated from Universiti Teknologi Mara in Computer Science. Currently, he works as a Programmer at Ixchel Corporation (M) Sdn. Bhd that built various online application platform for Education/SME. He is placed at Development and Support team handling education and management system. His specialties are system development for e-learning, online assessment, timetable and online payment and payment gateway.

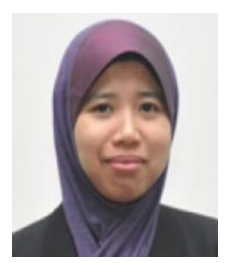

Wan Faezah Abbas obtained her BSc (Hons) Information Technology from Universiti Teknologi MARA, Malaysia. She holds an MSc Information Systems Engineering from UMIST, Manchester, United Kingdom. She worked with various system integration companies as a software engineer and worked with Motorola Inc. as a test engineer. She is now a senior lecturer at the Faculty of Computer and Mathematical Sciences, UiTM Malaysia.

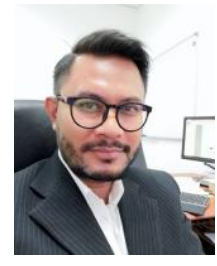

Dr. Mohd Izuan Hafez is currently attached to Universiti Putra Malaysia as a Senior Lecturer. He got a PhD from Deakin University, Australia. His current research is focusing in Security, Privacy and Blockchain.

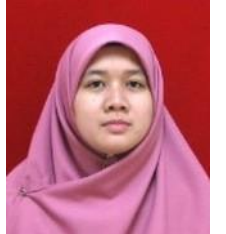

Dr. Nur Nafhatun Md Shariff is a Senior Lecturer at Academy of Contemporary Islamic Studies (ACIS) at Universiti Teknologi MARA (UiTM), Malaysia. Her academic qualifications are BA Syariah (Hons) (Astronomi Islam), MSc (Astronomi Islam) and Ph.D (Sains \& Teknologi) from University Malaya, Malaysia. Her area of expertise is Astronomi Islam. 